\title{
A Review of the Cross-Cultural Equivalence of Frequently used Personality Inventories
}

\author{
JÉRÔME ROSSIER \\ Institut de Psychologie, Université de Lausanne, BFSH 2 Dorigny, CH-1015, Lausanne, Switzerland \\ (E-mail: Jerome.Rossier@unil.ch)
}

Received: July 2004; Accepted: December 2004

\begin{abstract}
Personality inventories are frequently used for career guidance. Some should theoretically depend on cultural context, while others are supposed to be universal. The cross-cultural equivalence is only partial for culture-dependent models, as the locus of control. Concerning models that are supposed to be universal like the one proposed by Cattell or the Five-Factor Model, a partial and a full structural equivalence are, respectively observed. The extent of the scalar equivalence is difficult to assess indicating that more studies should be conducted to understand how culture affects processes underlying the evaluation of personality.
\end{abstract}

Résumé. Un examen de l'équivalence transculturelle de plusieurs inventaires de personnalité fréquemment utilisés. Les inventaires de personnalité sont fréquemment employés en orientation professionnelle. Certains devraient théoriquement dépendre du contexte culturel, alors que d'autres sont censés être universels. Pour les modèles qui dépendent de la culture, comme le lieu de contrôle, l'équivalence transculturelle est seulement partielle. Pour ce qui concerne les modèles qui sont censés être universels, comme celui proposé par Cattell ou comme le Modèle à Cinq Facteurs, on observe une équivalence structurale respectivement partielle et totale. Il est difficile d'évaluer l'ampleur de l'équivalence des échelles, ce qui montre que davantage d'études devraient être entreprises pour comprendre comment la culture affecte les processus sous-tendant l'évaluation de la personnalité.

Zusammenfassung. Eine Betrachtung der interkulturellen Entsprechungen einiger häufig verwendeter Pesönlichkeits-Inventarien. Persönlichkeits-Inventarien werden in er Berufsberatung häufig verwendet. Einige sollten theoretisch von kulturellen Kontexten abhängig sein, während andere als universell betrachtet werden. Die interkulturelle Vergleichbarkeit für kulturabhängige Modelle, wie etwa der Kontrollüberzeugung, besteht nur teilweise. Im Hinblick auf Modelle, die universell sein sollen wie das von Cattell vorgeschlagene Modell oder das Fünf-Faktoren-Modell, können sowohl partielle als auch vollstrukturelle Entsprechungen vorgefunden werden. Das Ausmaß er graduellen Entsprechungen ist kaum zu bewerten, was darauf hinweist, dass weitere Untersuchungen zu der Frage durchgeführt werden sollten in welcher Weise die Kultur diejenigen Prozesse beeinflusst, die der Beurteilung der Persönlichkeit zu Grunde liegen.

Resumen. Revisión de la equivalencia cross-cultural de diversos inventarios de personalidad frecuentemente utilizados. Los inventarios de personalidad suelen usarse con frecuencia en la orientación para la carrera. Algunos deberían depender teóricamente del contexto cultural, mientras que otros se supone que son universales. La equivalencia cross-cultural sólo es parcial en los modelos dependientes de la cultura, como el locus of control. Respecto a los modelos supuestamente universales como el propuesto por Cattell, o el Modelo de Cinco Factores, se observa una equivalencia parcial y una equivalencia total estructural respectivamente. El grado de la equivalencia escalar es difícil de medir, lo que indica que deberían realizarse más estudios de este tipo para entender cómo la cultura afecta a los procesos subyacentes en la evaluación de la personalidad.

Career counsellors use a great number of well-researched instruments designed to measure internal variables; these include career beliefs, career maturity, interests, skills, aptitudes, abilities, personality traits or values (Kapes \& 
Whitfield, 2001). During counsellor's interventions, educational and vocational options are often guided by the use of assessment (Harris-Bowlsbey, 2003). In one-to-one counselling or group guidance with adults, personality traits are frequently assessed. In France, personality traits assessment is conducted with $96 \%$ of adult clients (Lagabrielle \& Pouchard, 2003). Personality is usually assessed according to two theoretical perspectives. According to the first perspective, personality assessment is one element that helps clients develop a more accurate self-perception (Hammond, 2001). Increasing knowledge of the world of work, occupations, and the self would help clients analyze their strengths, weaknesses, opportunities, and threats and facilitate the process of career decision and transitions (Rossier, Berthoud \& Dauwalder, 2003). According to the second and more traditional perspective, personality is one aspect that might be taken into account when considering person-environment fit (Dawis \& Lofquist, 1984; Holland, 1985). This theory is roughly based on the idea that well-adapted individuals and occupations share common psychological characteristics. The degree of congruence between individual characteristics and the occupational environment is expected to result in positive outcomes (Gelso \& Fassinger, 1992), such as job satisfaction or job performance (Kieffer, Schinka \& Curtiss, 2004).

Conceptually, personality traits have traditionally been distinguished from both interests and abilities. Nevertheless, several recent studies have confirmed consistent associations between certain personality traits and vocational behaviour (Tokar, Fischer \& Subich, 1998). A recent meta-analysis carried out by Barrick, Mount, and Gupta (2003) showed meaningful and consistent relations between the "Big Five" model of personality and Holland's (1985) RIASEC hexagonal model of interests. The most consistent links were positive associations of Openness with Artistic and Investigative Interests, and of Extraversion with Enterprising and Social Interests. These links reflect specific associations between traits and interests (Sullivan \& Hansen, 2004). Internal locus of control (LOC) seems to be associated with an increase of interests in a variety of vocational themes (Mullis \& Mullis, 1997). These associations might indicate that individuals are likely to develop interests in accordance with their preferred ways of thinking, feeling, and acting.

Concerning the relation between personality and vocational indecision, several studies suggest that Neuroticism or negative affectivity underlies career indecisiveness, and that positive affectivity may predispose to higher decisionmaking abilities. Career indecision variables correlate moderately with several personality variables and especially with anxiety (Lucas \& Wanberg, 1995; Weinsten, Healy \& Ender, 2002), depression, and external LOC (Saunders, Peterson, Sampson \& Reardon, 2000). A study by Savickas, Briddick and Watkins (2002), which investigated the relation between career maturity and personality, shows that the attitudinal dimension (planning and exploration) was negatively associated with internalisation and positively with the orientation 
to social norms, and that the cognitive dimension (decision-making and fund of information) was positively associated with the level of realization that denotes the degree of effective functioning an individual has achieved.

Personality traits are also predictive of organizational outcomes such as job performance or job satisfaction. The meta-analysis by Hurtz and Donovan (2000) found that Conscientiousness and Emotional Stability are correlated with job performance when the criteria are pooled. A weak but positive correlation is usually observed between internal LOC and job performance. Recently, Hogan and Holland (2003) reported that all dimensions of the Five-Factor Model (FFM) predicted significantly specific criteria of job performance. Concerning the relation with job satisfaction, Judge and Bono (2001) reported a positive correlation with internal LOC and a negative correlation with Neuroticism.

There is still a debate about the interface between personality and cognition. Some authors argue that cognitive processes might contribute to personality development; others consider that personality provides the framework how individuals make use of and control cognitive abilities. Nevertheless most studies have shown weak correlations between personality traits and intelligence (Holland, Dollinger, Holland \& MacDonald, 1995). Ackerman and Heggestad (1997) found that some intelligence measures such as general intelligence, fluid intelligence, crystallized intelligence are positively, but weakly related to personality traits such as Extraversion, and Openness, and negatively related to personality traits such as Neuroticism. Interestingly, most intelligence measures are not related with Conscientiousness or LOC.

The correlations between interest, intelligence, and personality traits are not high enough to suggest that one can substitute for the other. This suggests that personality inventories might be complementary to vocational interest or intelligence measurements in career counselling and vocational guidance. Personality assessment can be especially useful in describing the client's strengths and weaknesses and might help him/her make more appropriate occupational choices. Moreover, personality variables might inform about the client's emotional skills.

The most frequently used personality inventories have been translated into a large number of languages. For example, the Sixteen Personality Factor questionnaire (16PF) or the NEO Personality Inventory (NEO-PI) have been translated into more than 40 languages and validated in numerous countries. Thus, the same inventories are used with people from a great variety of cultures. Moreover the cultural diversity of societies increases as a result of important population shifts. For this reason, counsellors frequently work with clients from different cultures or cultural minorities. In this context, data about the cross-cultural equivalence of the instruments used, and thus of the personality inventories are of prime importance (Marsella \& Leong, 1995). Indeed, career counsellors must know whether their assessment methods have any 
cross-cultural relevance in order to improve multicultural career counselling. Cross-cultural research into existing instruments might consolidate contemporary knowledge about existing instruments or promote development of culture-specific tools (Leong \& Hartung, 2000). Usually, methodologists distinguish three forms of psychometric equivalence: structural equivalence in which correlations between variables are identical in different groups; measurement unit equivalence, in which, in addition, the metric of the scales are identical; and full score or scalar equivalence in which the origin of the scale is also the same for the different groups. Cross-cultural studies of personality structure clearly raise the question of structural equivalence, and cross-cultural comparisons of mean scores require, or assume, measurement unit and scalar equivalence.

\section{Personality and structural equivalence}

Personality theories differ in the origins they ascribe to traits. The FFM or Zuckerman, Kuhlman, Joireman, Teta, and Kraft's Alternative Five-Factor Model (1993), argue that traits are biologically based, pointing to evidence that the five factors and their structure can be inherited (McCrae, Jang, Livesley, Riemann, \& Angleitner, 2001). In contrast, social learning theory emphasizes the importance of the environment, and reinforcement occupies a central position in the development of patterns of behaviour. This theory is the origin of Rotter's (1966), Locus of Control construct (LOC), which is based on the hypothesis that personal history leads to particular expectancies about the probability of occurrence of a generalized reinforcement. Thus, the FFM should be replicated across cultures, whereas according to the social learning theory, the structure of the LOC should vary across cultures.

\section{Structural equivalence of personality measurements based on the Five-Factor Model}

The FFM is a hierarchical model and its main postulate is that five broad dimensions adequately map personality traits. The NEO-PI-R, the 16PF5, and the ZKPQ-III are three widely used personality inventories measuring five similar higher-level personality dimensions.

The NEO-PI-R (Costa \& McCrae, 1992) was specifically designed to assess the five main dimensions of the FFM: Neuroticism (N), Extraversion (E), Openness (O), Agreeableness (A), and Conscientiousness (C). Over the past decade, a large number of cross-cultural researches have been conducted to investigate the universal validity of the FFM using the NEO-PI-R. In most cases, studies confirmed the structural replicability of the NEO-PI-R and, therefore, of the FFM. Costa, McCrae, and Jónsson (2002) compared the 
factorial structure obtained in 10 European countries to the American normative structure, and found that the mean congruence coefficients (CCs) were, respectively of $.97, .96, .95, .97$, and .97 for $\mathrm{N}, \mathrm{E}, \mathrm{O}, \mathrm{A}$, and $\mathrm{C}$ (p. 68). A congruence is considered to be high if $\mathrm{CC}>.90$, to be borderline if $.90 \geq \mathrm{CC}>.80$, and poor if $\mathrm{CC} \leq .80$. A review by Rolland (2002) based on a reanalysis of data from 16 cultures (from Asia, Europe, and America) shows that $\mathrm{N}, \mathrm{O}$, and $\mathrm{C}$ are highly replicable across countries. The orientation of the $\mathrm{E}$ and $\mathrm{A}$ factors in varimax rotations varies somewhat across cultures and especially in collectivist cultures, where these factors are recombined into two factors interpreted as Love versus Hate and Submission versus Dominance. This difference is quite subtle, because when targeted factor rotations are used, the factor structures are highly similar to the American normative structure with a mean coefficient of congruence of .93 . Recently, Rossier, Dahourou, and McCrae (2005) compared the structure observed in Burkina Faso and Switzerland with those observed in France and the US. The total congruence coefficients were all above .90. However, as in most Asian and African cultures, internal consistencies were generally lower in Burkina Faso, especially where the O-domain is concerned. One hypothesis proposed by the authors is that in collectivistic cultures, behaviour is determined more by social context than by traits.

Cattell (1957) used the lexical method to develop the 16PF and suggested grouping these 16 primary dimensions into global scales allowing for the description of personality structure at a higher level. In the fifth edition of the 16PF (16PF5), five global scales are proposed (Cattell \& Cattell, 1995): Extraversion (Ex), Anxiety (An), Tough-mindedness (Tm), Independence (In), and Self-control $(\mathrm{Sc})$. These global scales are similar to the five domains of the FFM of personality, except for the A domain of the FFM which is only poorly represented in Cattell's model (Rossier, Meyer de Stadelhofen, \& Berthoud, 2004). Several studies analyzed the cross-cultural replicabiltiy of the primary structure of the $16 \mathrm{PF}$ and observed that most of the 16 factors are stable across countries (Hofer \& Eber, 2002). However, almost no study analyzed the crosscultural replicabiltiy of the second-order structure even if this inventory has been translated into numerous languages and is probably one of the most used personality questionnaire. Aluja, Rossier, García and Verardi (2005) have recently compared the second-order structure of the 16PF5 in Spain and Switzerland and observed that only Ex, An, and In obtained CCs considered as high. The congruence was borderline for Sc and poor for Tm. This is apparently due to the fact that in the Swiss sample a clear five-factor structure was not found, and that a four-factor structure could better represent the observed data (Rossier et al., 2004). This difference in the second order factor structures could be due to both sample size and slight lexical differences in the formulation of items. However, these results are in accordance with those found by 
Golden (1978) who compared the second order structures in two samples of Hawaiian students, one of Japanese and one of European ancestry.

Zuckerman and colleagues (1993) developed an Alternative FFM (AFFM) by conducting an exploratory factor analysis of 33 personality scales selected from eight personality inventories. After studying different structures, they concluded that a five-factor structure was the most adequate solution. They developed the Zuckerman-Kuhlman Personality Questionnaire (ZKPQ) to capture these five basic personality factors: Impulsive Sensation Seeking (ImpSS), Neuroticism-Anxiety (N-Anx), Aggression-Hostility (Agg-Host), Sociability (Sy), and Activity (Act). Contrary to the original FFM, the Openness domain was not included in this model. The ZKPQ has been translated into several languages including Chinese, German, Japanese, or Spanish. However, no published research has systematically investigated the cross-cultural replicability of the structure of the AFFM proposed by Zuckerman and colleagues (1993). Having translated the ZKPQ into French, Rossier, Verardi, Massoudi and Aluja (submitted) compared the Swiss structure with the Spanish and with the original American structure (personal communication, Zuckerman, November 2004) and observed high CCs for all five dimensions of the AFFM (see Table 1).

The cross-cultural study of structural equivalence is an important way of establishing the validity of a personality model claiming that personality is a universal feature of the human species. Several models claim that five broad dimensions are sufficient to adequately map personality and several instruments allow for the assessing of these "Big Five" dimensions. However, the cross-cultural equivalence of these instruments was not equally studied. The structure underlying the NEO-PI-R was extensively studied, whereas the structure underlying the 16PF5 or the ZKPQ was only rarely investigated. Nevertheless, the investigations reported on indicate that the NEO-PI-R and the ZKPQ have a high cross-cultural equivalence, whereas the 16PF5 seems more sensitive to the cultural context. Concerning the NEO-PI-R, the crosscultural equivalence is particularly high in individualistic countries and slightly lower in collectivistic cultures. These results suggest that five independent dimensions adequately map personality, but that not all inventories have an equally stable structure across cultures or languages.

TABLE 1

Factor congruence coefficients comparing the Swiss structure of the ZKPQ-III to the Spanish and American structures

\begin{tabular}{lcccccc}
\hline & \multicolumn{5}{c}{ ZKPQ-III dimensions } & \\
\cline { 2 - 6 } \multicolumn{1}{c}{ Sample (N) } & ImpSS & N-Anx & Act & Sy & Agg-Host & Total CC \\
\hline Swiss (843) and Spanish (1,006) & .94 & .95 & .89 & .91 & .92 & .93 \\
Swiss (843) and American (2,383) & .96 & .96 & .95 & .94 & .93 & .95 \\
\hline
\end{tabular}




\section{Structural equivalence of locus of control}

The LOC construct has generated enormous interest since its definition by Rotter (1966). LOC refers to individual differences in the extent to which people perceive events as depending on their own person (internal control) versus the extent to which they believe that reinforcement depends upon an external factor (external control). The most popular instrument to assess LOC is Rotter's I-E scale (Rotter, 1966). It is a one-dimensional scale that opposes internal to external control. Dyal (1984) provides an extensive review of cross-cultural research into LOC and numerous factor-analytic studies were conducted in different countries with various assessment instruments. Most studies have observed that Rotter's I-E scale is not one-dimensional. Data from different countries have often enabled two factors to be identified corresponding to dimensions of personal and socio-political control. Nevertheless, Dyal points out that structural equivalence is generally not found for LOC measurements. Levenson (1974) proposed a three-dimensional model made up of an Internality dimension (I) and of two externality dimensions, Powerful Others (P) and Chance (C). Recently, Smith, Trompenaars and Dugan (1995) conducted a transcultural research across 43 countries using Rotter's scale and identified three dimensions relatively close to the ones postulated by Levenson (1974). Moreover, Ghorpade, Hattrup and Lackritz (1999), using multiple group structural equations modelling, found that James's LOC scale was structurally equivalent in American and Indian samples.

In a recent study, Rossier and colleagues (2005) examined LOC in Burkina Faso and Switzerland using Levenson's IPC. The total CC was .77. For the scales, the congruence was borderline for $\mathrm{I}(\mathrm{CC}=.89)$, and $\mathrm{C}(\mathrm{CC}=.86)$, and poor for $\mathrm{P}(\mathrm{CC}=.52)$. The poor fit of LOC's structure across the two countries was due to the fact that another structure better describes LOC. A two-factor solution was indeed considered replicable with CCs for factors of, respectively .97 and .91. These two factors corresponded to an external and an internal dimension, which are similar to the two dimensions observed by previous authors (Dyal, 1984). LOC might only be partly influenced by cultures. Authors proposed that from the perspective of FFM, LOC might be a characteristic adaptation, subject to both dispositional and environmental influences.

\section{Personality and metric or scalar equivalence}

Comparison of mean levels across cultures should ideally only be carried out when structural, metric, and scalar equivalence have been demonstrated, even through metric and scalar equivalence are difficult to assess. Different versions of the same inventory might not be directly comparable, and any observed 
differences might be caused by a translation bias, a difference in response styles, or differences due to the sample selection.

Metric or scalar equivalence of personality measurements based on the FiveFactor Model

Structural equivalence was systematically studied only for the NEO-PI-R for personality measurements based on the FFM. Several studies have used bilingual samples and found that the distortion due to translation is very small. McCrae (2002) conducted a factor analysis at the culture-level on 114 age- and gender-defined sub samples from 36 cultures. He observed that the five factors extracted were very similar to the usual structure seen in analyses of individuallevel data. When comparing this culture-level structure with the American normative structure, the total $\mathrm{CC}$ was of .90 , which is very high considering the small number of sub samples. Moreover, in order to validate these culture-level factors, McCrae correlated them with culture-level values for the Eysenck Personality Questionnaire (EPQ) and with Hofstede's (2001) dimensions of culture. At this culture-level, $\mathrm{N}$ and $\mathrm{E}$ were significantly correlated with their EPQ counterparts $(r>.50)$. N was associated to Power Distance and Masculinity. E was associated to low Power Distance, low Long-Term Orientation, and Individualism. $\mathrm{O}$ was associated to low Power Distance, Individualism, and Masculinity. A was associated to low Uncertainty Avoidance and $\mathrm{C}$ was associated to Power Distance (McCrae, 2002). To compare the mean-scores, the data of these 36 cultures were standardized using the American norms and controlling for sex and age. Some consistent variability was observed for the standard deviations. Indeed, collectivistic cultures seem to be associated with lower SDs, which could also explain the lower reliability that is usually observed in these countries (indeed, coefficient alpha is related with the range of variation). However, mean scores comparison across 36 cultures led to meaningful results. Similar cultures also have similar culture-level personality profiles. However, the magnitude of the differences between cultures is generally very modest.

Rossier and colleagues (2005) achieved a culture-level comparison of personality profile using the NEO-PI-R in Burkina Faso and Switzerland. They observed that despite the important cultural differences between these two countries, mean differences between Burkinabè and Swiss are relatively small as stated by the age-corrected effects sizes reported in Table 2 . The effect size for $\mathrm{O}$ is medium, which was also credited by the lowest $\mathrm{CC}$; culture accounts for nearly $15 \%$ of the variance. The effect size for $\mathrm{N}, \mathrm{E}$, and $\mathrm{C}$ is small, and the effect size for $\mathrm{A}$ is even smaller; culture accounts for less than $5 \%$ of the variance. The Burknabès scored lower in $\mathrm{E}$ and $\mathrm{O}$, and higher in $\mathrm{C}$ than the Swiss. On average, Burkinabè describe themselves in a similar way as Black South Africans and Zimbabweans, as more serious, conventional, and cautious 
TABLE 2

Descriptive statistics corrected for age for Switzerland and Burkina Faso and estimated effect size $\left(\eta^{2}\right)$ and significance for country, gender, and interaction effects

\begin{tabular}{|c|c|c|c|c|c|c|c|}
\hline \multirow[b]{2}{*}{ NEO-PI-R } & \multicolumn{2}{|c|}{ Burkina Faso } & \multicolumn{2}{|c|}{ Switzerland } & \multicolumn{3}{|c|}{ Effect size $\eta^{2}$} \\
\hline & Mean & SE & Mean & $\mathrm{SE}$ & Country & Gender & Country $\times$ Gender \\
\hline $\mathrm{N}$ & 103.9 & 1.03 & 95.2 & .76 & $.028 * * *$ & $.028 * * *$ & $.005^{* *}$ \\
\hline $\mathrm{E}$ & 104.0 & .86 & 109.5 & .63 & $.031 * * *$ & .002 & $<.001$ \\
\hline $\mathrm{O}$ & 106.6 & .84 & 121.9 & .60 & $.144 * * *$ & .002 & $.009 * *$ \\
\hline A & 117.1 & .88 & 120.6 & .64 & $.008^{* *}$ & $.012 * * *$ & $.008 * *$ \\
\hline $\mathrm{C}$ & 115.6 & .98 & 110.7 & .73 & $.012 * * *$ & $<.001$ & .001 \\
\hline
\end{tabular}

$* p<.05 ; * * p<.01 ; * * * p<.001$.

than the Swiss. This comparison shows that there are associations between culture and the mean level of personality traits, however it cannot determine the causal sequence involved. Indeed, mean trait levels might be influenced by the cultural environment, or might simply represent long-standing ethnic differences in the distribution of traits. This type of comparison has never been conducted using the ZKPQ and only one study was performed using the 16PF5 (Aluja et al., 2005), which was found not to have a high structural equivalence. For this reason, mean-level comparison seems difficult to conduct.

\section{Metric or scalar equivalence of $L O C$}

The structural equivalence of LOC measurements has not consistently been observed. However several studies have compared different ethnic groups or cultures for mean levels (Dyal, 1984). Differences between Americans and Europeans are usually small, whereas differences between Americans and East Asians are larger. East Asians tend to score higher on externality and lower on internality. Smith and colleagues (1995) compared the mean scores of 43 countries according to three dimensions: Personal-Political, Individual-Social, and Luck. Several clusters have been identified confirming the grouping of culturally similar countries. For example, one cluster included countries from Eastern Europe and was characterized by high scores on the Personal-Political dimension. A high score on the Social-Individual dimension characterized another cluster which includes countries from Western Europe and South America.

Rossier and colleagues (2005) in their culture-level comparison identified the same two-factor LOC structure in Burkina Faso and Switzerland. The first factor was an Externality dimension and the second factor was an Internality dimension. On average, Burkinabè scored higher on the Externality factor than Swiss; culture accounts for $15 \%$ of the variance. The difference on the 
Internality dimension was small; culture accounts for less than $1 \%$ of the variance. This pattern of differences is in line with previous research (Dyal, 1984). Nevertheless, the two samples are not equivalent from the point of view of socio-economic status, which has a well-documented effect on LOC. Once again, the differences that are plausibly due to culture are small.

\section{Discussion}

Personality measurements are frequently used in career guidance, and this in a great number of countries. In this context, data concerning cross-cultural equivalence is of prime importance. Nevertheless, the cross-cultural equivalence was not always systematically studied for these inventories. Several researches analyzed the structural equivalence of the NEO-PI-R or LOC measurements, but almost none were conducted for the 16PF5 or the ZKPQ. For the instruments a theory claiming that five factors are sufficient to adequately map personality traits, and that these factors should be universal, high cross-cultural equivalence should be observed. The NEO-PI-R and the ZKPQ seem to have a high structural equivalence, and this especially in Western countries, whereas the 16PF5 has a much lower structural equivalence. Thus, the FFM and the AFFM seem to be reasonable frames to study personality traits across cultures. For the LOC, which is theoretically more dependent on cultural context and which should be less stable across cultures, it seems that some factors are stable across cultures, suggesting that at least part of LOC may represent a common disposition. Personality measurements are used in a large number of countries. For this reason it seems very important to study more systematically the structural equivalence of these instruments as it has been done for RIASEC measures (Rounds \& Tracey, 1996). This is very important to assess the cross-cultural applicability of personality measures.

The metric and scalar equivalence are very difficult to assess. McCrae (2002) claims that personality measurement might be more robust than expected on the basis of empirical data showing, for example, that differences due to translation are very small. Usually differences across countries are very small, but not insignificant, meaning that existence of culturally specific norms is a prerequisite for using personality inventories (Marsella \& Leong, 1995). Interestingly, culture has not the same influence on all personality dimensions. For example, Openness mean-level seems more sensitive to culture than Agreeableness. Moreover, mean-level differences observed with instruments that should be theoretically more dependent on cultural context as LOC measurements are not larger than those observed with instruments, which are theoretically less dependent on the cultural context, such as the NEO-PI-R. Mean-level analyses are interesting not only for assessing metric or scalar equivalence, which might be difficult, but also for achieving better understanding 
of how culture affects processes underlying self-perception. In this area more research is needed.

\section{Implications for personality assessment with culturally diverse populations}

Personality assessment is a useful supplement to vocational interests and ability assessment (Ackerman \& Heggestad, 1997; Sullivan \& Hansen, 2004). It enables some strengths and weaknesses to be described, which might help clients in making more appropriate occupational choices. When counsellors use a translated instrument, particular attention should be paid to its cultural validity. Not to consider cultural replicability can result in erroneous conclusions about the personalities of clients. Our results suggest that the FFM is stable across cultures and might therefore be appropriate for personality assessment in various cultural settings. Nevertheless, the replicability of the Tough-Mindedness dimension of the 16PF5 is low. This implies that this dimension might have slightly different meanings in Spain and Switzerland, for example. The identification of culture-specific characteristics implies that counsellors need to be familiar with the tradition of clients as stated by the American Psychological Association guidelines for clinicians (APA, 1990).

The linguistic, conceptual, and scale equivalences are not the only important aspects that need to be considered. The normative equivalence is also a crucial aspect, as most professional psychologists are aware of. Mean-level comparisons indicate that there are some culture-specific patterns, which implies that norms for a particular personality inventory need to be available for it to be used for career counselling or vocational guidance. Neglect in considering normative equivalence can again result in erroneous conclusions about the personalities of clients. A version in the client's mother tongue should be used. For bicultural clients, results should be compared against the norms of both cultures.

To summarize, analyses of the structural equivalence makes it possible to compare different personality measurements and models. A model made up of five broad dimensions, like the FFM or the AFFM, might be a reasonable frame to study personality across cultures. Mean-level comparisons lead to meaningful differences even if scalar equivalence is not reached. However, personality assessment can only be conducted once the cultural replicability of the inventory is established and culture-specific norms are available. Moreover, it is of prime importance that consultants be familiar with the tradition of their clients. Obviously, further studies need to be conducted in order to better understand how the cultural context affects the processes underlying personality assessment. 


\section{Acknowledgements}

This research was supported by a fellowship from the Swiss National Science Foundation.

\section{References}

Ackerman, P. L., \& Heggestad, E. D. (1997). Intelligence, personality, and interests: Evidence for overlapping traits. Psychological Bulletin, 121, 219-245.

Aluja, A., Rossier, J., García, L. F., \& Verardi, S. (2005). The 16PF5 and the NEO-PI-R in Spanish and Swiss samples: A cross-cultural comparison. Journal of Individual Differences, 26, 53-62.

American Psychological Association (1990). Guidelines for providers of psychological services to ethnic, linguistic and culturally diverse populations. Washington, DC: Author.

Barrick, M. R., Mount, M. K., \& Gupta, R. (2003). Meta-analysis of the relationship between the Five-Factor Model of personality and Holland's occupational types. Personnel Psychology, 56, 45-74.

Cattell, R. B. (1957). Personality and motivation structure and measurment. New York: World Book.

Cattell, R. B., \& Cattell, H. E. P. (1995). Personality structure and the new fifth edition of the 16PF. Educational and Psychological Measurement, 55, 926-937.

Costa, P. T. Jr., \& McCrae, R. R. (1992). Revised NEO Personality Inventory (NEO-PI-R) and NEO Five-Factor Inventory (NEO-FFI) professional manual. Odessa, FL: Psychological Assessment Resources.

Costa, P. T. Jr., McCrae, R. R., \& Jónsson, F. H. (2002). Validity and utility of the Revised NEO Personality Inventory: Examples from Europe. In B. De Raad, \& M. Perugini (Eds.), Big Five assessment (pp. 61-77). Göttingen: Hogrefe \& Huber Publishers.

Dawis, R. V., \& Lofquist, L. H. (1984). A psychological theory of work adjustment: An individual differences model and its application. Minneapolis: University of Minnesota.

Dyal, J. A. (1984). Cross-cultural research with the locus of control contruct. In H. M. Lefcourt (Ed.), Research with the locus of control construct (Vol. 3, pp. 209-306). New York: Academic.

Gelso, C. J., \& Fassinger, R. E. (1992). Personality, development, and counseling psychology: Depth, ambivalence, and actualization. Journal of Counseling Psychology, 39, 275-298.

Ghorpade, J., Hattrup, K., \& Lackritz, J. R. (1999). The use of personality measures in crosscultural research: A test of three personality scales across two countries. Journal of Applied Psychology, 84, 670-679.

Golden, C. J. (1978). Cross-cultural second order factor structures of the 16PF. Journal of Personality Assessment, 42, 167-170.

Hammond, M. S. (2001). The use of the Five-Factor Model of personality as a therapeutic tool in career counseling. Journal of Career Development, 27, 153-165.

Harris-Bowlsbey, J. (2003). A rich past and a future vision. Career Development Quarterly, 52, 18-25.

Holland, D. C., Dollinger, S. J., Holland, C. J., \& MacDonald, D. A. (1995). The relationship between psychometric intelligence and the Five-Factor Model of personality in a rehabilitation sample. Journal of Clinical Psychology, 51, 79-88.

Holland, J. L. (1985). Making vocational choices: A theory of vocational personalities and work environments. Englewood Cliffs, NJ: Prentice Hall.

Hofer, S. M., \& Eber, H. W. (2002). Second-order factor structure of the Cattell Sixteen Personality Factor Questionnaire. In B. De Raad, \& M. Perugini (Eds.), Big Five assessment (pp. 397-409). Göttingen: Hogrefe \& Huber Publishers.

Hofstede, G. (2001). Culture's consequence: Comparing values, behaviors, institutions, and organizations across nations (2nd ed.). Thousand Osks, CA: Sage.

Hogan, J., \& Holland, B. (2003). Using theory to evaluate personality and job-performance relations: A socioanalytic perspective. Journal of Applied Psychology, 88, 100-112.

Hurtz, G. M., \& Donovan, J. J. (2000). Personality and job performance: The Big Five revisited. Journal of Applied Psychology, 85, 869-879.

Judge, T. A., \& Bono, J. E. (2001). Relationship of core self-evaluations traits - self-esteem, generalized self-efficacy, locus of control, and emotional stability - with job satisfaction and job performance: A meta-analysis. Journal of Applied Psychology, 86, 80-92. 
Kapes, J. T., \& Whitfield, E. A. (2001). A counselor's guide to career assessment. Tulsa, OK: National Career Development Association.

Kieffer, K. M., Schinka, J. A., \& Curtiss, G. (2004). Person-environment congruence and personality domains in the prediction of job performance and work quality. Journal of Counseling Psychology, 51, 168-177.

Lagabrielle, C., \& Pouchard, D. (2003). Champs et outils d'investigation lors du bilan de compétences: Relations avec les attentes et issues en termes de plans d'action [Application fields and investigation tools for professionnal skills assessment: Relations between expectations and outcomes in terms of action plans]. In B. Simon (Ed.), Actes du colloque: La place de l'évaluation dans le processus d'orientation professionnelle des adultes [Proceedings of the Conference: Purpose of assessment in the career counselling process] (pp. 41-48). Lomme: Association nationale pour la Formation Professionnelle des Adultes.

Leong, F. T. L., \& Hartung, P. J. (2000). Cross-cultural career assessment: Review and prospects for the new millennium. Journal of Career Assessment, 8, 391-401.

Levenson, H. (1974). Activism and powerful others: Distinctions within the concept of InternalExternal control. Journal of Personality Assessment, 38, 377-383.

Lucas, J. L., \& Wanberg, C. R. (1995). Personality correlates of Jones' three-dimensional model of career indecision. Journal of Career Assessment, 3, 315-329.

Marsella, A. J., \& Leong, F. T. L. (1995). Cross-cultural issues in personality and career assessment. Journal of Career Assessment, 3, 202-218.

McCrae, R. R. (2002). NEO-PI-R data from 36 cultures: Further intercultural comparisons. In R. R. McCrae, \& J. Allik (Eds.), The Five-Factor Model of personality across cultures (pp. 105125). New York: Kluwer Academic/Plenum Publishers.

McCrae, R. R., Jang, K. L., Livesley, W. J., Riemann, R., \& Angleitner, A. (2001). Sources of structure: Genetic, environmental, and artifactual influences on the covariation of personality traits. Journal of Personality, 69, 511-535.

Mullis, A. K., \& Mullis, R. L. (1997). Vocational interests of adolescents: Relationships between self-esteem and locus of control. Psychological Reports, 81, 1363-1371.

Rolland, J.-P. (2002). The cross-cultural generalizability of the Five-Factor Model of personality. In R. R. McCrae, \& J. Allik (Eds.), The Five-Factor Model of personality across cultures (pp. 728). New York: Kluwer Academic/Plenum Publishers.

Rossier, J., Berthoud, S., \& Dauwalder, J.-P. (2003). Quel est le rôle de l'évaluation de la personnalité pour le bilan de compétences? [What is the relevance of personality measurement for professional skills assessment]. In B. Simon (Ed.), Actes du colloque: La place de l'évaluation dans le processus d'orientation professionnelle des adultes [Proceedings of the Conference: Purpose of assessment in the career counselling process] (pp. 113-123). Lomme: Association nationale pour la Formation Professionnelle des Adultes.

Rossier, J., Dahourou, D., \& McCrae, R. R. (2005). Structural and mean level analyses of the FiveFactor Model and Locus of Control: Further evidence from Africa. Journal of Cross-Cultural Psychology, 36, 227-246.

Rossier, J., Meyer de Stadelhofen, F., \& Berthoud, S. (2004). A comparison of the hierarchical structures of the NEO-PI-R and of the 16PF5. European Journal of Psychological Assessment, $20,27-38$.

Rossier, J., Veradi, S., Massovdi, K., \& Aluja, A. (submitted). Validation of the Alternative FiveFactor Model at the domain and facet level in a French-speaking sample.

Rounds, J., \& Tracey, T. J. (1996). Cross-cutlural structural equivalence of RIASEC models and measures. Journal of Counseling Psychology, 43, 310-329.

Rotter, J. B. (1966). Generalized expectancies for internal versus external control of reinforcement. Psychological Monographs, 80, (Whole No. 609).

Saunders, D. E., Peterson, G. W., Sampson, J. P. Jr., \& Reardon, R. C. (2000). Relation of depression and dysfunctional career thinking to career indecision. Journal of Vocational Behavior, 56, 288-298.

Savickas, M. L., Briddick, W. C., \& Watkins, C. E. Jr. (2002). The relation of career maturity to personality type and social adjustment. Journal of Career Assessment, 10, 24-41.

Smith, P. B., Trompenaars, F., \& Dugan, S. (1995). The Rotter locus of control scale in 43 countries: A test of cultural relativity. International Journal of Psychology, 30, 377-400. 
Sullivan, B. A., \& Hansen, J.-I. C. (2004). Mapping associations between interests and personality: Toward a conceptual understanding of individual differences in vocational behavior. Journal of Counseling Psychology, 51, 287-298.

Tokar, D. M., Fischer, A. R., \& Subich, L. M. (1998). Personality and vocational behavior: A selective review of the litterature 1993-1997. Journal of Vocational Behavior, 53, 115-153.

Weinsten, F. M., Healy, C. C., \& Ender, P. B. (2002). Career choice anxiety, coping, and perceived control. Career Development Quarterly, 50, 339-349.

Zuckerman, M., Kuhlman, D. M., Joireman, J., Teta, P., \& Kraft, M. (1993). A comparison of three structural models for personality: The Big Three, the Big Five, and the Alternative Five. Journal of Personality and Social Psychology, 65, 757-768. 